\title{
Impact of Pandemic COVID-19 to the Online Learning: Case of Higher Education Institution in Malaysia
}

\author{
NurHaiza Bt Nordin*, NurNaddia Bt Nordin \\ Faculty of Entrepreneurship and Business, Universiti Malaysia Kelantan, Malaysia
}

Received September 6, 2020; Revised November 17, 2020; Accepted November 29, 2020

\section{Cite This Paper in the following Citation Styles}

(a): [1] NurHaiza Bt Nordin, NurNaddia Bt Nordin, "Impact of Pandemic COVID-19 to the Online Learning: Case of Higher Education Institution in Malaysia," Universal Journal of Educational Research, Vol. 8, No. 12A, pp. 7607 - 7615 , 2020. DOI: 10.13189/ujer.2020.082546.

(b): NurHaiza Bt Nordin, NurNaddia Bt Nordin (2020). Impact of Pandemic COVID-19 to the Online Learning: Case of Higher Education Institution in Malaysia. Universal Journal of Educational Research, 8(12A), 7607 - 7615. DOI: 10.13189/ujer.2020.082546.

Copyright $\odot 2020$ by authors, all rights reserved. Authors agree that this article remains permanently open access under the terms of the Creative Commons Attribution License 4.0 International License

\begin{abstract}
This study aim is to examine and evaluate the impact of COVID-19 on education systems, which is the implementation of online learning (OL) during Movement Control Order (MCO) to higher learning education institution in Malaysia. A questionnaire was developed, and a random sampling of data was performed. Three hundred and fifty-two samples were collected using the Smart PLS-Structural Equation Modeling (SEM) technique to analyze the results. The study shows that acceptance, usability, satisfaction, and technical skills play a pivotal role in inspiring online learning effectiveness for the institution of higher education. Such consideration allows the entire higher education institution in Malaysia to recognize the importance of online learning in education in a consistent way. All the factors influence the sustained positive efficacy except acceptance of online learning. The present study covers only the institutions of higher learning. Entire elementary and secondary school students also participate in online learning, so this group can also be included for further studies. The research would continue to develop the online learning environment, and the study of higher education organizations is gradually embracing learning as an alternative to conventional classroom learning for current students and as a means to extend its scope to new students. Adopting online learning and its technologies requires significant investment in the staff, resources, energy, and space that administrators and those in educational leadership need to be justifiable. Just a few have explored the effect of COVID-19 on the education system and how online learning are conducted during MCO and using Smart PLS is a novel concept and it is a
\end{abstract}

research of its kind from first hand.

Keywords COVID-19, Online Learning, Acceptance, Usability, Satisfaction, Technical Competencies, Smart PLS

\section{Introduction}

Schools and higher education institutions have been challenged by significant shifts in diverse contexts due to the COVID-19 and Malaysia Movement Control Order (MCO). With modern gadgets and the Internet, students today grow up. Its practices are also distinct from those of the previous generation. As such, identifying these differences and designing educational suitable for their learning styles, characteristics, and attitudes are challenges faced by educational practitioners and designers. Students' expectation and their satisfaction with online learning courses have received significant interest from educational practitioners. Student expectations and their satisfaction with online learning courses have received significant interest from educational professionals and researchers. However, for all levels of students' elementary, secondary, to higher-level institutions, an observational study of online learning performance. Acceptance, satisfaction, accessibility, and online learning technical competencies are the metrics used in this study for the success of online learning and are still to be seen at all levels of students. In previous 
research, this analysis addresses differences.

The reach of e-learning is online learning, which takes place only via the internet. The use of internet technology to provide a wide variety of information and performanceenhancing solutions [33] refers to e-learning. According to [23], e-learning encompasses Web-based learning (WBL), Internet-based training (IBT), and automated distribution of learning (ADL), and online learning (OL). Besides, e-learning offers instruction in a wider sense through all interactive platforms, such as the internet, intranets, extranets, and hypertext/hypermedia documents [10]. The reach of e-learning includes networks, higher education, K-12 schools, corporation, government offices, non-profit organizations, households, and public spaces [33]. In that respect, educators will use e-learning to increase the quality and efficacy of instructional programs when dealing with social, science, and pedagogical problems. Using online learning as an e-learning tool, students can typically access online lessons at any time and place they have internet access. Different course management systems used for online learning enable synchronous as well as asynchronous communication between students and instructors.

During the COVID-19 pandemic at the time of the Malaysia Movement Control Order (MCO), much of the schooling for students is using online learning. Besides, online learning also enhances student-to-student and lecturer-to-student communication skills, allows student-centered instructional strategies, provides 24/7 access to course materials, provided just in time methods for determining and evaluating students' needs. However, online learning at the time of the Malaysia Movement Control Order (MCO) is successful in producing a higher school enrolment.

This study was conducted in public and private universities, with student participation for a higher education institutions. A web-based survey was developed with online learning classes to understand the acceptance, satisfaction, usability, and technical skills of the students. The research aimed to collect 350 higher learning responses. The purpose of this research is to explore the relationship between acceptance, satisfaction, usability, and technical skills with online learning and thirdly to examine the role of interaction in the online learning process.

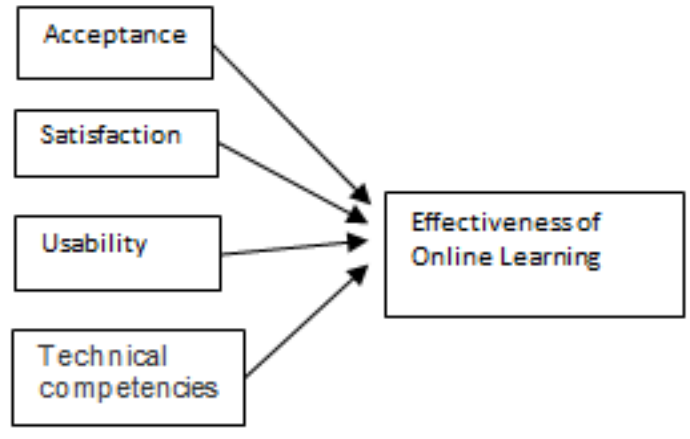

Figure 1. Research Framework

\section{Literature Review}

All aspect of people's lives has been invaded by information technology (IT). The way individuals, businesses and organizations present, disseminate, and communicate their messages is transforming technology, generating an omnipresent learning experience, and speeding up the information society. One of the key strategic fields will reach a high degree of knowledge learning and management in an information society. Against this context, IT has broadened the area of education and brought a new element of excellence to the ever-changing notion of educational quality. With rapid technological advances in mind, educators are now taking a second step into the very center of learning and are still looking for innovative approaches to the production of learning. Teachers are inspired to use these new technical products more efficiently. Students are now facing more open spaces where they can receive self-initiated tuition, enabling them to engage in lifelong learning. With these difficulties and opportunities in mind, some researchers have highlighted the ability of online courses to promote the present creation of pedagogy and learning environment focused explicitly on constructivist concepts [11] and [37].

Literature notes that the creation of personal knowledge about the outside world of encouraged by constructivist learning environments. This mechanism is facilitated by experiences representing realities through real-world, case-based learning contexts and encouraging the creation of common knowledge. Significant concerns have been posted, on the other hand especially concerning the quality of e-learning. Since online learning without physical interaction is self-directed learning, and the level of engagement has been the focus of debate about how to improve performance. Many researchers [18] and [29], centered on connectivity as the main feature of online learning in terms of content. On the other hand, [29] proposed three forms of interactivity; a) material interaction (cognitive presence); b) teacher interaction (teaching presence); and c) classmate interaction (social presence).

While [39] interpreted the 'fourth wave' of online technology as a means of enhancing engagement and thereby improving quality [6], it indicated a framework composed of three building blocks of input-process-output in the learning process against learning/teaching objectives. Despite the rising need for and the interest in enhancing the standard of interaction within the hospitality discipline of online learning, there is little types of research on the quality of interaction and student perceptions of performance. Acquiring awareness and information about the needs of the students would be the starting point for diagnosing the present state of online learning in hospitality. As such, the purposed of this analysis is to explore the relationship between perceived 
interaction characteristics.

This analysis is focused on the implementation in fulfillment of these objectives of the online principle proposed by [6]. One of the students' performance drivers of an online program is online learning, a sense of belonging to the learning community, encouragement, peer and family support, time management skills, and increased communication with the teacher [12]. E-learning provides different benefits, according to [5] and [34]. All the advantages found in the literature are accessibility, time and location versatility, avoidance of campus traffic, a wide range of course choices, lifelong learning, social integration and networking, more advanced knowledge, financial benefits, and multimedia-rich content.

Studies conducted by [21], [30], and [34] also demonstrated that online e-learning can be as successful as traditional face-to-face classroom learning for student achievement. E-learning technology can promote student-based learning and help create a shared learning community as well. Student-centered e-learning encourages students to fully engage in the course of learning and measure the pace of their learning.

In applying collaborative and constructivist theories, particularly in conjunction with the use of internet tools, the benefits of student-centered learning are increasing significantly [37]. According to e-learning studies [19], e-learning is used as a compulsory alternative to teaching and learning in higher education around the world. Despite its relevance and success, many concerns exist concerning for to its usage and effectiveness.

Universities face problems with the poor use of e-learning by students and even academic staff. This research examines the adoption of e-learning by students at universities using an updated TAM paradigm consisting of six constructs, including instructor characteristic, machine self-efficacy, course architecture, perceived utility, perceived ease of use, and intention to use. This results from Tunku Abdul Rahman University College (TARUC), Johor, with 95 undergraduates' students. The knowledge was analyzed using SEM. Results found that computer self-efficacy has a substantial impact on user-friendliness, while the perceived user-friendly line significantly affects the desire to use e-learning.

E-learning has many excellent benefits, providing everyone with flexible instruction and equal schooling [32]. [32] has radically improved the self-study process because of the opportunity to tailor and efficiently satisfy the learners' demands. The findings showed that it was important to provide facilities and technologies, human capital, climate, evaluation, management and delivery, support, and pedagogical aspects.

In several institutions of higher education, including Malaysia [40], blended learning has been widely used. Therefore, teachers and universities need to be well-equipped with sufficient expertise and skills to allow the effective application of blended learning. The finding reveals that there are positive satisfaction of the learners with the blended learning employed at their institution. In the case of Al-Madinah International University in Malaysia, the admission model for e-learning services should be tested [41]. The results point to the use of e-learning knowledge as the aspect that directly shaped the desire to make the most of e-learning behavior. These causes have also had the largest indirect influence on the application of e-learning for behavioral purposes. To put it simply, students' use of e-learning environments can be explained mainly by their appreciation of the added benefit of these environments, which is highly informed by their interest in web-based experiences and computer-assisted learning.

It consists of four independent variables, namely playfulness, teacher, teaching tools, characteristic and content design; and two belief variables, which is perceived utility and perceived ease of use and a contingent variable which is an intention to use e-learning [27]. These studies indicate that the efficiency of e-learning programs increases the learners' efficiency.

Studied e-learning satisfaction among learners in Pakistan. The findings of this study show that the students were largely pleased with teaching e-learning systems [3]. These study findings are backed by previous studies, as it has identified some clear benefits of e-learning programs that make students more relaxed. The benefits of online services, for instance, include on-demand training, the removal of geographic access limitation, the reduction of travel costs for attendance, and the reduction of the classroom building and/or repair fees [4].

The estimation of the relative importance of usability design characteristics in an e-learning curriculum based on student's expectations was examined [1]. The studies have shown that the most important dimension followed by e-learning system navigation is the quality of information. The report also showed that system learning and graphic design were third and fourth in order of significance in e-learning application usability assessment. Finally, the least relevant interface areas that influenced the usability evaluation of the e-learning system were instructional assessment and system interactivity. This study's analytical results help provide programmers and evaluators with observations, leading to a more efficient approach to optimizing the usability of the e-learning environment and consideration such as learning, userfriendliness, technological technology, usability policy, community and gender. For student sustainability reasons, the e-learning website would have superior availability. The experience and/or lack of experience of the students in this study may not have much connotation because the principle of understanding and experience is ultimately at the same stage, but their satisfaction and expectation are optimistic in establishing a standard to enhance the usability features in the development process of the 
e-learning website.

\section{Research Model}

The design of the conceptual framework on exploratory research is built based on the literature. Each has four independent or exogenous variables. Using Smart PLS software, the conceptual model for the proposed framework is developed. Independent variables are the main factors that will impact online learning effectiveness in higher education institutions. The dependent variable is the effectiveness of OL which is the key factor in generating quality students for higher education. This demographic contains only whole students for higher education institutions who create applications

The study was carried out in Malaysia on a random group of 315 students. First a qualitative analysis was performed for the higher education institution focused on interviews and experiences with the students. In higher learning institutions, a survey questionnaire was developed based on the conceptual framework and distributed to the different students. The sample size of any statistical system has a direct effect on the statistical strength. In general, to detect the true difference, a researcher needs a very broad sample size while the distribution of dependent variables is skewed and the effect size is minimal. The study [16] recommended the creation of a model with a sample size of 200 on average. According to [13], in the case of SEM, the sample size parameters are influenced by four elements: misspecification of the model, the scale of the model, variations from normality, and procedures for estimation. The influence of sample size can be marginal on the potential of the model to be reliably calculated to detect design error if the model incorporates all the relevant build and indication into the theory. If the model includes all the theory's relevant structures and metrics, the influence of sample size can be marginal on the ability of the model to reliably calculate design error detection.

PLS-SEM is beneficial when used with small sample sizes, but some researchers abuse this advantage by depending on extremely small samples compared to the population. According to [9], the effect size is 84 sample size for the sample size using four number of predictors, so the total sample size used matched the study. The data obtained from the questionnaire was entered in the MS-Excell and stored as a.csv file while can be supported by various statistical tools to perform reliability testing. The factors defined based on the description in the conceptual model (Figure 1) were operationalized by four endogenous and one exogenous and the variable influencing the software quality. For this research analysis, one exogenous and the variable that influenced software quality were operationalized and used to collect the data. Four independent (exogenous) variables and indicators were defined for this research study such as acceptance, usability, satisfaction, and technical competencies on online learning.

One dependent variable is online learning efficacy since the conceptual model used exploratory research. Selected for all indicators were a multi-item, five-point, bipolar Likert scale ranging from "strongly disagree" (1) to "strongly agree" (5). For each independent variable, the item ratings were summed to form a summary rating scale. However, as this is the first study of its kind inside exploratory testing, all of the things were explicitly written for this research. A measurement model and assessment according to Hair et al., the formal evaluation parameters follow a two-step process with separate evaluation of measurement models and structural model. Next, construct validity should be tested for the assessment of the reflective measurement model. The validity of the construct consisting of two important components is convergent validity and discriminant validity. The convergent validity assesses factor loading, composite reliability, and Average Variance Extracted (AVE) and the discriminating validity evaluates cross-loading, Fornell, and Larcker and HTMT.

Assessment of Convergent Validity Convergent validity refers to "the extent to which a measure (indicators) positively correlates with alternative measures (indicators) of the same construct". Table 1 shows the specifics of each construct used in the conceptual framework and indicators associated with each construct are listed in the column named "Item". First the composite reliability is verified and any value below the threshold values of 0.7 needs to be assessed. This is established by checking the indicator reliability values. Any values in the indicator which is below 0.4 should be removed from the constructs and any value between 0.4 and 0.6 can be retained if it increases the AVE and CR values. After removing the indicators from the constructs, the details of the remaining constructs and their corresponding convergent validity scores have met the threshold values for CR $>0.7$ and AVE $>0.5$ respectively.

\section{Result and Discussion}

\subsection{Validity and Reliability Tests}

Validity and usability assessments were administered to determine the accuracy and reliability of the questionnaire. To test the value of the Pearson correlation coefficient at a meaningful level $(\alpha)$ of 5 percent, a validity check was carried out. For a 0.05 degree of significance, the test used one-side steps. The evaluation criteria were 10 if the instruments were declared true by $r$ count $>r$ table, and; 2) if the instrument was declared invalid by $r$ count $<\mathrm{r}$ table. The instrument used was correct since all instruments in 
the validity test had a $r$ count meaning $(\alpha) 5$ percent $>r$ table with a 5 percent meaning.

The evaluation parameters were 1) if the $r$ count $>r$ table declared the instrument valid; and 2) if the $r$ count $<r$ table declared the instrument non-valid. Because all instruments in the validity test had $\mathrm{r}$ count meaning $(\alpha)$ $5 \%>\mathrm{r}$ table with $5 \%$ meaning, the instrument used was valid. The reliability research used Cronbach's alpha values for this study that measured the precision of the measuring instrument. The research instrument was either correct or reliable in qualifying since Cronbach's alpha value was 0.891 . The validity and reliability assessments carried out show the validity of the research instrument's reliability.

\subsection{Analysis with Smart PLS}

Using the Smart-PLS method assisted by Smart PLS 3.0, a model of influential design change factors was built in the construction projects. Then, the validity and reliability of the model were evaluated. Then it tested the validity and reliability of the model. Convergent and discriminating validity was tested for validity, while the alpha and composite durability of Cronbach was checked for reliability. The convergent validity rule of thumb is 1) the load factor $>0.7$ where the lease factor $0.6-0.7$ is still ideal for exploratory work, 2) the load factor $>0.6$ and 3) the mean dependent variance $(\mathrm{AVE})>0.5$. For design modification, Figure 2 shows the smart PLS calculation model.

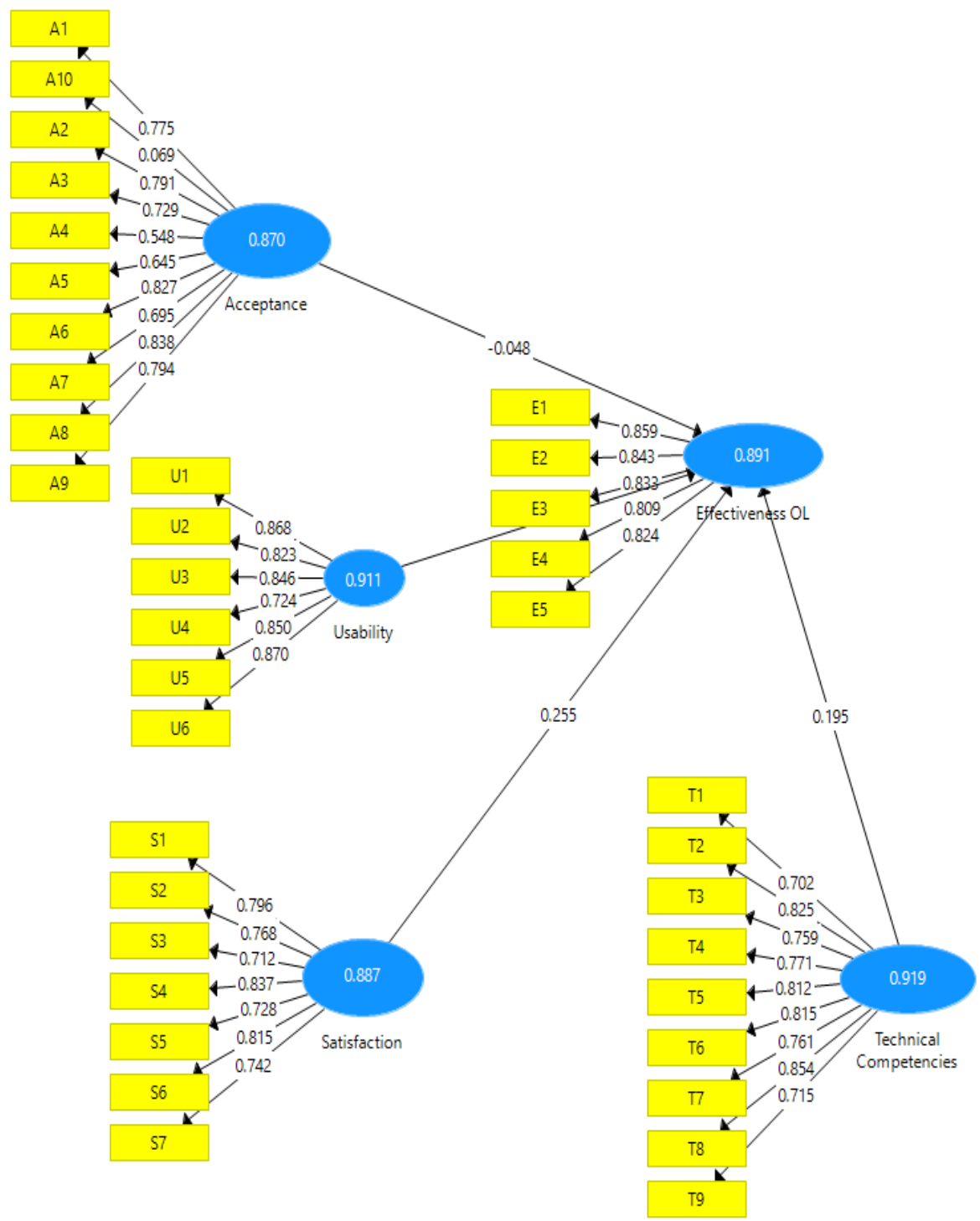

Figure 2. Measurement Model of Design Change (Source: Results Analysis with SmartPLS) 
Table 1. Internal Consistency, Convergent Validity, composite reliability and AVE

\begin{tabular}{|c|c|c|c|c|c|}
\hline Construct & Indicator & Loadings & Cronbach's alpha & $\begin{array}{l}\text { Composite } \\
\text { Reliability } \\
\end{array}$ & AVE \\
\hline \multirow{11}{*}{ Acceptance } & $\mathrm{A} 1$ & 0.775 & \multirow{8}{*}{0.896} & \multirow{8}{*}{0.916} & \multirow{8}{*}{0.553} \\
\hline & $\mathrm{A} 2$ & 0.792 & & & \\
\hline & $\mathrm{A} 3$ & 0.730 & & & \\
\hline & A4 & 0.547 & & & \\
\hline & A5 & 0.643 & & & \\
\hline & A6 & 0.827 & & & \\
\hline & A7 & 0.695 & & & \\
\hline & A8 & 0.838 & & & \\
\hline & A9 & 0.794 & \multirow{7}{*}{0.911} & \multirow{7}{*}{0.931} & \multirow{7}{*}{0.692} \\
\hline & U1 & 0.869 & & & \\
\hline & $\mathrm{U} 2$ & 0.823 & & & \\
\hline \multirow{4}{*}{ Usability } & $\mathrm{U} 3$ & 0.843 & & & \\
\hline & $\mathrm{U} 4$ & 0.726 & & & \\
\hline & U5 & 0.854 & & & \\
\hline & U6 & 0.870 & & & \\
\hline \multirow{7}{*}{ Satisfaction } & S1 & 0.796 & \multirow{7}{*}{0.887} & \multirow{7}{*}{0.912} & \multirow{7}{*}{0.597} \\
\hline & S2 & 0.768 & & & \\
\hline & S3 & 0.712 & & & \\
\hline & S4 & 0.837 & & & \\
\hline & S5 & 0.728 & & & \\
\hline & S6 & 0.815 & & & \\
\hline & S7 & 0.742 & & & \\
\hline \multirow{8}{*}{ Technical Competencies } & $\mathrm{T} 1$ & 0.702 & \multirow{9}{*}{0.919} & \multirow{9}{*}{0.933} & \multirow{9}{*}{0.610} \\
\hline & $\mathrm{T} 2$ & 0.825 & & & \\
\hline & $\mathrm{T} 3$ & 0.759 & & & \\
\hline & $\mathrm{T} 4$ & 0.771 & & & \\
\hline & $\mathrm{T} 5$ & 0.812 & & & \\
\hline & $\mathrm{T} 6$ & 0.815 & & & \\
\hline & $\mathrm{T} 7$ & 0.761 & & & \\
\hline & $\mathrm{T} 8$ & 0.854 & & & \\
\hline \multirow{6}{*}{$\begin{array}{l}\text { Effectiveness of Online } \\
\text { Learning }\end{array}$} & T9 & 0.715 & & & \\
\hline & E1 & 0.859 & \multirow{5}{*}{0.891} & \multirow{5}{*}{0.919} & \multirow{5}{*}{0.696} \\
\hline & E2 & 0.843 & & & \\
\hline & E3 & 0.833 & & & \\
\hline & E4 & 0.809 & & & \\
\hline & E5 & 0.824 & & & \\
\hline
\end{tabular}

Source: Authors' estimates based on survey data

The load factor values, Cronbach's alpha values, composite reliability values, and AVE values are shown in Table 2. George and Mallery (2003) stated that with more than 0.7 (alpha $>0.9$ ), Cronbach's alpha is outstanding. In the current review, more than 0.9 is excellent. Besides within the current study set, AVE will be equal to or greater than 0.5 and composite reliability will be more than sufficient. In comparison, the discriminative validity is seen in Table 2. Moreover discriminant validity is shown in Table 2. Using Smart PLS 3, a structural model was evaluated after the evaluation of the measurement model. Direct and indirect effects were analyzed to attain this objective. Consideration of the route coefficient and the value " $\mathrm{t}$ " verified the hypothesis. Besides it investigated R-Squared $\left(\mathrm{R}^{2}\right)$ and quantitative significance $\left(Q^{2}\right)$. 
Table 2. Discriminant Validity (HTMT)

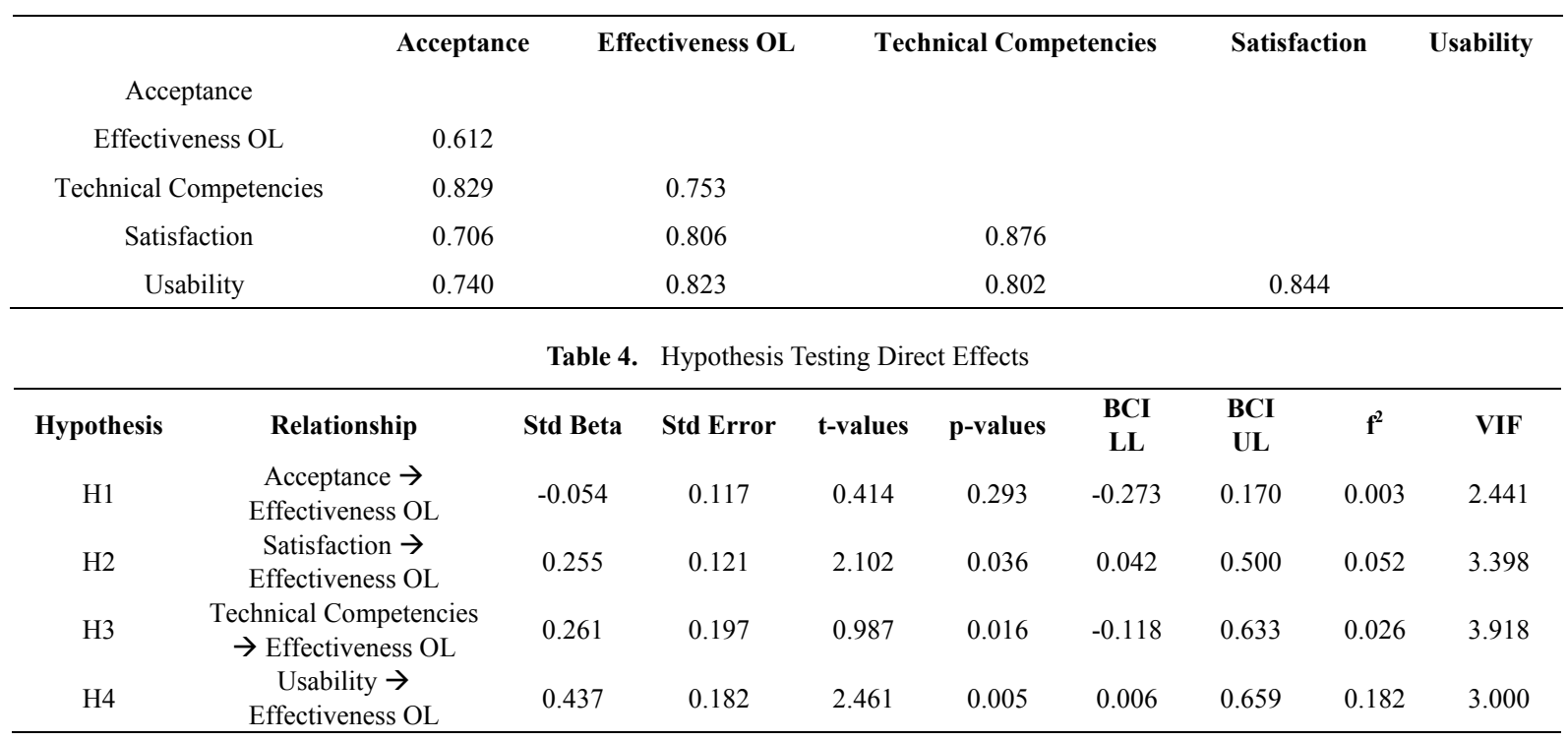

Note: We use a $95 \%$ confidence interval with a bootstrapping of 5,000

\subsection{Structural Model}

We evaluate multivariate skewness and kurtosis, as indicated by [14]. The findings revealed that the data obtained was not multivariate natural, the multivariate skewness of Mardia's multivariate skewness $(\beta=5.115$, $\mathrm{p}<0.01)$ and Mardia's multivariate kurtosis $(\beta=62.566$, $\mathrm{p}<0.01$ ), so we recorded the path coefficient, the standard deviations, $\mathrm{t}$-values and $\mathrm{p}$-values for the structural model using a 5,000 sample, re-sample bootstrapping method following the recommendations of [14]. It was also based on the suggestion of [15] that p-values are not a good criterion for evaluating the validity of the experiment and proposed that parameters such as p-values, confidence ratios, and impact sizes be included in a mixture. The description of the parameters we have used to assess the established hypotheses as seen in Table 4.

We first tested the influence of the 3 predictors on OL efficacy. $\mathrm{R}^{2}$ was 0.633 , which indicates that 63.3 percent of the variation in OL efficacy was explained by all 4 predictors. Acceptance $(\beta=-0.054, \mathrm{p}>0.10)$, Satisfaction $(\beta=0.255, \mathrm{p}<0.01)$, technical competencies $(\beta=0.261, \mathrm{p}$ $<0.10)$ and usability $(\beta=0.195, \mathrm{p}>0.10)$. H2, H3, and $\mathrm{H} 4$ were all positively linked to OL efficacy, so H2, H3 and $\mathrm{H} 4$ were supported, but $\mathrm{H} 1$ are negatively related to the effectiveness of OL and not significant, thus $\mathrm{H} 1$ was rejected.

\section{Conclusions}

This study aims is to investigate the effect of pandemic COVID-19 on the education system of higher learning institutions by analyzing the hypothesized model i.e. "Acceptance of Students-Effectiveness Online Learning" in higher education institutions. Only two constructs are accepted from the four hypotheses tested, and the t-value obtained shows that they are statistically important. This research also discusses the validity and reliability of the measures used, and the results indicate strong convergent validity and discriminating validity. The satisfaction, usability, and technical competencies are positively related to the effectiveness of online learning for higher education institution students. This is supported by [3]. They find that students were satisfied with the e-learning mode of teaching. Another study conducted by [27] and [1] has shown that the quality of knowledge is the most significant dimension followed by the navigation of the e-learning system. According to [17] and [32], students' interest in research was increased by an e-learning program or a website with a harmonious color and context configuration. The factor of acceptance of student for online learning negatively affects the effectiveness of online learning during the MCO because the student used fully online learning to study for the first time, thus most of them cannot accept this new norm. Besides that, the student also may have a certain problem during online learning such as time management, the environment of the study, and others that have a major impact on their acceptance of online learning. The results showed, in conclusions, that all the theories are backed by empirical research and by following per under with previous observations and theoretical context.

\section{REFERENCES}

[1] Alsherri, A.A., Rutter, and Smith. "An Implementation of the UTAUT Model for Understanding Students' Perceptions of Learning Management Systems: A Study Within Tertiary Institutions in Saudi Arabia”, International Journal of 
Distance Education Technologies. Volume 17, Issue 3. pp 123-128, 2015.

[2] Arbaugh, J. B., \& Benbunan-Fich, R. "The importance of participant interaction in online environments", Decision Support Systems, 43(3): 853-865, 2007.

[3] Ayub. N and Iqbal, S. "Student Satisfaction with e-Learning achieved in Pakistan, Asian Journal of Distance Education", The Asian Society of Open and Distance Education. ISSN 1347-9008 Asian J D E Vol 9, No 2, pp 26 - 31, 2011.

[4] Bataineh, E. A summary look at Internet based distance education.2001

[5] Bates, A.W., \& Bates, T. "Technology, E-learning and Distance Education”, Psychology Press, 2005

[6] Benbunan-Fich, R., Hiltz, S.R., and Harasim, L. "The Online Interaction Learning Model: An Integrated Theoretical Framework for Learning Networks", 2005.

[7] Büyüközkan, G., Ruan, D., \& Feyziog lu, O. "Evaluating e-learning Website quality in a fuzzy environment", International Journal of Intelligent Systems. 22, 567-586, 2007.

[8] Chiu, C., Hsu, M., \& Sun, S. "Usability, quality, value and e-learning continuance decisions", Computers \& Education, 45, 399-416, 2005.

[9] Green, S.B. "How many subjects does it take to do a regression-analysis", Multivariate Behavioural Research, Vol. 26 No. 3, pp. 499-510 1991.

[10] Govindasamy, T. "Successful im-plementation of e-Learning; Pedagogical considerations". The Internet and Higher Education, 4(3-4), 287-299, 2002.

[11] Harasim, L. "Shift Happens Online Education as a New Paradigm in Learning", Internet and Higher Education, Vol (3), pp 41-61, 2000.

[12] Hart, C. Factors Associated with Student Persistence in an Online Program of Study: A Review of the Literature. Journal of Interactive Online Learning, Volume 11, Number 1, pp 19-42.

[13] Hair, J., Anderson, R., Tatham, R.L., \& Black, W.C. Multivariate data analysis, (5th ed.), NJ: Upper Saddle River, Prentice-Hall. 1998

[14] Hair, J. F., Hollingsworth, C. L., Randolph, A. B., \& Chong, A. Y. L. An updated and expanded assessment of PLS-SEM in information systems research. Industrial Management \& Data Systems, 117(3), 442-458, 2017a.

[15] Hahn, E.D. and Ang, S.H. "From the Editors: New Directions in the Reporting of Statistical Results in the Journal of World Business. Journal of World Business, 52(2), pp 125-125, 2017.

[16] Hoelter, J. W. (1983). The Analysis of Covariance Structures: Goodness-of-Fit Indices. Sociological Methods \& Research, 11, 325-344, 1983.

[17] Hong, K.S., Lai, K.W., \& Holton, D. (2003). Students' satisfaction and perceived learning with a Webbased course. Journal of Educational Technology \& Society 6(1). Retrieved January 15, 2004, fromhttp://ifets.ieee.org/period ical/vol_1_2003/v_1_2003.html.
[18] Hiltz, S. R. "The virtual classroom: Learning without limits via computer networks", Norwood, NJ: Ablex, 1994.

[19] Ibrahim R, Leng N S, Yusoff R C M, Samy G N, Masrom S, Rizman Z I. "E-learning acceptance based on technology acceptance model (tam)", J. Fundam. Appl. Sci., 9(4S), 871-889, 2017.

[20] Jurczyk, J., Benson, S. K., \& Savery, J. "Measuring student perceptions in Web-based courses: A standards-based approach", Online Journal of Distance Learning Administration. Retrieved November, 17, 2009, from: http://www.westga.edu/ distance/ojdla/winter74/jurczyk74. $\mathrm{htm}$

[21] Johnson, S. D., S. R. Aragon, N. Shaik, and N. Palma-Rivas. Com-parative analysis of learner satisfaction and learning outcomes in online and face-to-face learning environments. Journal of Interactive LearningResearch11 (1): 29-49. 2000.

[22] Kiget, N.K., Wanyembi, G. and Peters, A.I. "Evaluating Usability of E-Learning Systems in Universities.",(IJACSA) International Journal of Advanced Computer Science and Applications, Vol. 5, No. 8,pp. 97-118, 20.14

[23] Khan,B.H. “A Framework for Web-Based Learning”. In B.H. Khan (Ed), Web-based Traning. Englewood Cliffs, NJ: Educational Technology Publications (2001).

[24] Klobas, J. E., \& Clyde, L. A. "Learning to use the internet in a developing country: Validation of a user model", Libri, 48(3), 163-175, 2010.

[25] Klobas, J. E., \& McGill, T. J. "The Role of Involvement in Learning Management System Success", Journal of Computer High Education, 22, 112-134, 2010.

[26] Kort, W., \& Gharbi, J. (na). "An experiential approach of satisfaction in e-learning", Retrieved July 5, 2008, from http://www.canavents.com/its2008/abstracts/283.pdf

[27] Lee, B., Yoon, J., \& Lee, I. "Learners' acceptance of e-learning in South Korea: Theories and results", Computers \& Education, 53, 1320-1329, 2009.

[28] Mohamed Hussain Thowfeeka, M.H., and Abdul Salamb, M.N. 'Students' Assessment on the Usability of E-learning Websites", Procedia - Social and Behavioral Sciences No. 141.pp 916 - 922, 2014.

[29] Moore, M.G. "Three Types of Interaction", American Journal of Distance Education, No.3, Vol 2, pp. 1-7, 1989.

[30] Neuhauser, C. "Learning Style and Effectiveness of Online and Face-to-Face Instruction", American Journal of Distance Education. No.2, Volume 2. Pp. 99-113, 2002.

[31] Quyen Le Hoang Thuy To Nguyen, Phong Thanh Nguyen, Vy Dang Bich Huynh, Luong Tan Nguyen (2020). Application Chang's Extent Analysis Method for Ranking Barriers in the E-Learning Model Based on Multi-Stakeholder Decision Making. Universal Journal of Educational Research, 8(5), 1759 - 1766. DOI: 10.13189/ujer.2020.080512.

[32] Ramayah, T., Hwa, C.J. \& Chuah, F. "Partial Lease Square Structural Equation Modeling (PLS-SEM) using SmartPLS 3.0: An Update and Practical Guide to Satistical Analysis", Pearson Singapore, 2018.

[33] Rafaeli, S. and F. Sudweeks. 'Networked Interactivity', 
Journal of Computer-Mediated Communication 2(4), 1997.

[34] Rosenberg, M.J. "E-Learning: Strategies for Delivering Knowledge in the Digital Age", McGraw-Hill, New York, 2001.

[35] Russell, L.B. Modelling for Cost-Effectiveness Analysis. Statistic in Medicine.

[36] Smith G. G., Ferguson, D. \& Caris M. "Online vs face-to-face”, T H E Journal 28 (9), pp. 18-25, 2001.

[37] Sigala, M. Investigating the factors determining e-learning effectiveness in tourism and hospitality education. Journal of Hospitality \& Tourism Education, Vol. 16, No. 2, pp. 11 21, 2004.

[38] Strong, R. "Investigating Students' Satisfaction with eLearning Courses: The Effect of Learning Environment and
Social Presence", Journal of Agricultural Education. Volume 53, Number 3, pp 98-110, 2012.

[39] Taylor, J. C. (2001). Fifth generation distance education. e-Journal of Instructional Science and Technology (e-JIST), 4(1), 1-14, 2001.

[40] Umi Kalsom Masrom, Nik Aloesnita Nik Mohd Alwi, Nor Hazlin Nor Asshidin (2019). Understanding Learners' Satisfaction in Blended Learning among Undergraduate Students in Malaysia. Universal Journal of Educational Research, 7(10), 2233 - 2238. DOI: 10.13189/ujer.2019.071 023.

[41] Zawaideh, F.H.” Acceptance Model for e-Learning Services: A Case Study at Al-Madinah International University in Malaysia", International Journal of Academic Research in Accounting, Finance and Management Sciences Vol. 7, No.2, April 2017, pp. 14-20, 2017. 